\title{
As "confrarias" como um fenômeno organizacional brasileiro: uma reflexão sobre significados
}

\author{
Luis Claudio Miranda Mangi *
}

\begin{abstract}
Resumo
Apesar da grande quantidade de artigos acadêmicos sobre a importância dos grupos informais, produzidos nas últimas duas décadas, a maior parte dos estudos limitou-se à análise da influência das redes interorganizacionais na competitividade e na capacidade de mudança das empresas. Neste artigo, argumenta-se que os grupos informais são reproduções sociais do contexto onde estão inseridos, e que seu poder de influência precisa ser investigado numa perspectiva ampliada, interdisciplinar, onde o objeto possa ser analisado, simultaneamente, dos pontos de vista inter e intra-organizacional. Para isso, pretende-se realizar uma reflexão crítica sobre o fenômeno das "confrarias", as quais são vistas como grupos informais que emergem nas organizações a partir de valores socialmente construídos e compartilhados. 0 principal questionamento teórico é quanto à natureza dos valores e lógicas de ação compartilhados pelos seus participantes, dos recursos de poder de que dispõem e de como esses participantes utilizam tais recursos para atingir seus objetivos. É proposto um modelo analítico para explicar a dinâmica do processo de surgimento e legitimação das "confrarias", desenvolvido a partir dos mais recentes conceitos elaborados segundo a teoria institucional.
\end{abstract}

Palavras-chave: poder; redes sociais; teoria institucional; campos organizacionais; legitimação.

\begin{abstract}
In despite of an impressive accumulation of studies focusing on the importance of informal groups during the last decades, most of the work were limited to the influence of inter-organizational networks on competitiveness and on firms ability to promote organizational change. This article endorses the claim that informal groups are social reproductions of the context in which they are embedded. Therefore their influence power must be investigated under a broader and interdisciplinary perspective, where the object could be analyzed from both an inter and intra-organizational standpoint. For that purpose, this article attempts to undertake a critical reflection on the "fraternities" phenomenon: informal groups that emerged in organizations based on values socially built and shared. The major theoretical question is to understand the nature of the values and rationalities shared among its participants, what power resources they have available and how they use them to achieve their objectives. An analytical model is proposed to explain the dynamics of the rising and legitimation of the "fraternities", built upon concepts emerged from the most recent debate in Institutional Theory.
\end{abstract}

Keywords: power; social networks; institutional theory; institutional fields; legitimation.

\section{Introdução}

Desde meados do século passado, o estudo sobre os grupos informais têm atraído o interesse de pesquisadores na área das ciências sociais e comportamentais. Nas últimas duas décadas, um volume expressivo de trabalhos acadêmicos tem abordado a importância dos grupos informais, segundo as mais variadas perspectivas dentro do campo de estudo das organizações. No entanto, esse acúmulo de conhecimento não convergiu para um corpo teórico comum, o que gerou certa fragmentação desse campo de estudo (OLIVER e EBERS, 1998; POOLE et al., 2004). Além disso, a ênfase predominante nesses estudos limitou-se à análise da influência das redes interorganizacionais na capacidade de mudança, competitividade e adaptação das empresas.

Mestrando pela EBAPE/FGV. E-mail: luis.mangi@ terra.com.br.

Artigo recebido em maio de 2004 e aceito em junho de 2004 . 
Neste artigo, argumenta-se que os grupos informais são reproduções sociais do contexto onde estão inseridos, e que seu poder de influência precisa ser investigado numa perspectiva ampliada, interdisciplinar, onde o objeto possa ser analisado, simultaneamente, sob uma visão inter e intra-organizacional. Para tal, pretende-se realizar uma reflexão crítica sobre o fenômeno das "confrarias", aqui vistas, preliminarmente, como grupos informais que emergem nas organizações dentro de um contexto social, cultural e histórico particular, que é a sociedade brasileira, onde as relações pessoais são extremamente valorizadas, influenciando decisões e relações, e ditando um estilo peculiar de "fazer negócios".

Segundo Prates e Barros (1997), a cultura brasileira tende a produzir um modelo de gestão com fortes bases histórica e estrutural em nosso sistema social, modelo esse que é permeado por uma lógica personalista e autoritária. DaMatta (2001) defende a tese de que o brasileiro vive um trágico dilema, em que de um lado, temos o esqueleto nacional construído de leis universais que devem valer para todos, e do outro, situações onde cada qual busca seu próprio interesse, utilizando para isso o seu sistema de relações pessoais. O resultado é um sistema social dividido e, ao mesmo tempo, equilibrado "entre duas unidades sociais básicas: o indivíduo (o sujeito das leis universais que modernizam a sociedade) e a pessoa (o sujeito das relações pessoais, que conduz ao polo tradicional do sistema)" (DaMATTA, 2001, p.96-97).

A "confraria", como construção teórica, é resultado de uma observação atenta das complexas relações sociais que ocorrem no âmbito interno de algumas organizações nacionais e multinacionais no Brasil. Uma parte importante deste estudo é fruto das minhas experiências pessoais em empresas nas quais tive a oportunidade de ter contato direto nos últimos 10 anos com o fenômeno das "confrarias", seja como membro efetivo dessas organizações, seja através de longas conversas e debates com pessoas que, de alguma forma, também "vivenciaram" esse fenômeno em suas organizações.

O principal questionamento teórico é analisar a natureza dos valores e lógicas de ação compartilhados pelos participantes das "confrarias", os recursos de poder de que dispõem e de como esses participantes utilizam tais recursos para atingir seus objetivos. Visa também abordar os possíveis impactos das "confrarias" nos processos de gestão, na performance e na capacidade de mudança e inovação das organizações. O enfoque proposto é essencialmente descritivo, adotando uma visão desenvolvimentista e comparativa, a partir de alguns conceitos formulados nos debates mais recentes conforme a teoria institucional. Há, também, um objetivo ambicioso que é o de construir uma ponte entre o processo de formação das "confrarias" e o conceito de campo organizacional, elemento central dentro da abordagem institucional.

A perspectiva adotada não pretende ser exclusiva nem capaz de apreender a totalidade do objeto de estudo, mas pretende apontar algumas questões para um desenvolvimento teórico mais aprofundado sobre outros casos, indicando possíveis caminhos para investigações empíricas que possam corroborar e ampliar as teses aqui levantadas sobre as "confrarias".

\section{A evolução das proposições teóricas relacionadas ao homem e à organização informal}

As "confrarias" são um fenômeno singular mas, certamente, há pontos comuns entre essa interpretação e a noção de grupos informais, elemento presente em muitas correntes do pensamento organizacional. Aqui, é feito um breve relato sobre a evolução dos conceitos relacionados ao homem, particularmente, em relação ao conceito de organização informal. Procura-se identificar os méritos e limitações de algumas das abordagens que foram mais influentes nesse campo, indicando a base teórica que servirá como ponto de partida para a investigação do conceito "confrarias" e dos seus elementos característicos que permitem circunscrevê-lo como um objeto de estudo independente.

A emergência da sociedade industrial no início do século XX foi marcada pela consolidação da estrutura burocrática como modelo de organização ideal, pelo aperfeiçoamento dos sistemas de trabalho e pela busca contínua da máxima eficiência. É também nessa época que o estudo sobre as organizações ganha contornos mais nítidos, principalmente, em torno das idéias de Taylor e Fayol que estabelecem os pilares da escola clássica de administração. Essa perspectiva privilegiava o foco na estrutura interna das organizações, baseada no pressuposto da racionalidade absoluta. O homem era visto como um ser eminentemente racional, previsível 
e controlável, que, conhecendo todos os cursos de ação disponíveis, toma suas decisões com base no cálculo utilitário das consequiências, idéia central do conceito conhecido como homo economicus. Para os teóricos da escola clássica, o comportamento humano era considerado menos importante. Acreditava-se que incentivos financeiros apropriados, controle constante e treinamento seriam ações suficientes para assegurar uma boa produtividade, e que comportamentos inadequados seriam decorrentes de distorções na estrutura da organização ou de problemas na sua implementação. Essa abordagem ignorava a possibilidade de estudo das motivações intrínsecas dos indivíduos (MOTTA e VASCONCELOS, 2002).

Os primeiros movimentos de reação aos postulados racionalistas da escola clássica de administração buscavam um enfoque mais relacional na análise do ambiente interno das organizações. Essa reação surge a partir do desenvolvimento das ciências comportamentais, ganhando maior evidência a partir da década de 1930, principalmente com a publicação dos resultados dos estudos empíricos de Mayo (1933) na Western Electric. Essas pesquisas mostraram que aumentos de produtividade ou resultados melhores não dependiam somente de sistemas e regras mais eficientes ou das estruturas formais, mas estariam associados à melhoria do ambiente de trabalho. A partir dos estudos de Mayo, vários teóricos passaram a desenvolver estudos que começaram a valorizar mais o entendimento dos fatores afetivos e psicológicos, desenvolvendo práticas e modelos voltados para a melhoria do clima social e do ambiente de trabalho nas empresas. Essas idéias ajudaram a criar os fundamentos da escola de relações humanas - estabelecendo o conceito de homo social -, e tiveram o mérito de revelar a complexidade do comportamento humano nas organizações e de evidenciar outras necessidades comuns a todos os indivíduos além do incentivo financeiro, tais como a afetividade, a sociabilidade e a segurança. À medida que se intensificavam as interações interpessoais nas empresas, os indivíduos passavam a se organizar em torno de interesses e necessidades comuns. Esse fenômeno também atraiu a atenção dos teóricos de orientação comportamentalista. Resgatando estudos anteriores no campo da sociologia sobre o conceito de grupos primários, também é adotada a noção de "organização informal", elemento central das propostas da escola de relações humanas.

Entretanto, segundo Motta e Vasconcelos (2002), a escola de relações humanas - tal como os teóricos da escola clássica - ainda tinha uma visão limitada do papel do indivíduo nas organizações, pois via o homem como um ser passivo que reagiria de forma padronizada aos estímulos a que fosse submetido. De fato, as contribuições da escola de relações humanas pouco acrescentam ao entendimento do fenômeno das "confrarias" que se pretende alcançar neste artigo, oferecendo uma visão bastante restrita e estática da realidade organizacional. Essa perspectiva ignora as influências do ambiente externo que surgem naturalmente a partir das relações que as organizações estabelecem em seu domínio de atuação, e desconsidera outros vetores importantes no processo de formação da identidade social, como tempo e espaço, cultura, mecanismos de cognição e as interações que ocorrem entre os indivíduos e o seu espaço social durante o processo de socialização.

Trabalhos posteriores à escola de relações humanas foram desenvolvidos na década de 1960, a partir de argumentos ligados à psicologia, para tratar de conceitos como motivação e liderança; alguns deles utilizando a pirâmide de motivações de Maslow (1954), segundo a qual as necessidades humanas seriam hierarquizadas e modificáveis ao longo do tempo, de acordo com o desenvolvimento individual e social do ser humano (MOTTA e VASCONCELOS, 2002). As teorias da motivação e liderança entendem que o homem possui necessidades múltiplas e complexas, que não se restringem apenas à necessidade de filiação a grupos informais, tal como propunha a escola de relações humanas. $\mathrm{O}$ trabalho forneceria sentido à existência humana, orientando as ações dos indivíduos. A satisfação no trabalho estaria, portanto, diretamente associada ao desenvolvimento pessoal, à aprendizagem, à autonomia de pensamento e à auto-realização. Portanto, é proposto o conceito de homo complexo como um aperfeiçoamento do conceito de homo social, oferecendo-se uma nova perspectiva ao debate sobre o papel do homem nas organizações. Dentro de um enfoque cognitivista, os teóricos passaram a trabalhar com o conceito de identidade social como um elemento em construção permanente: dependendo dos valores e das características da identidade de cada indivíduo ou grupo de indivíduos, os objetivos e interesses seriam diferentes entre si, podendo se modificar ao longo do tempo, tornando a ação humana incerta e imprevisível.

Segundo Motta e Vasconcelos (2002), o processo de humanização do trabalho, que produziu uma série de modelos e técnicas que se tornaram muito populares no mundo empresarial, fundamenta-se a partir do conceito 
de homo complexo. Essa abordagem foi muito criticada por ter proposto um modelo "ideal" ao processo de construção da identidade social, representado pelo modelo unidimensional do "homem que se atualiza", calcado no pressuposto de que o ser humano constrói sua identidade e encontra sua auto-realização necessariamente nas relações de trabalho. Há de se considerar também, uma certa contradição nas propostas de valorização do homem no trabalho perante os imperativos do crescimento e da eficiência, tão presentes na realidade que as organizações enfrentavam (e ainda enfrentam...) no seu dia-a-dia. Tal ambigüidade pode ser explicada como uma tentativa de propor caminhos para empresas que, mesmo tendo adotado os rigorosos métodos da administração científica, apresentavam graves problemas de queda de produtividade, questão que o legado teórico racionalista da escola clássica não era capaz de responder.

Tenório (2002), em seus ensaios sobre teoria organizacional, também aponta limitações na proposta de "humanização", argumentando que, apesar de ter ampliado o enfoque por meio de contribuições trazidas da psicologia social, essa abordagem não conseguiu oferecer uma visão interdisciplinar da realidade, e que "não passou de uma visão paradisíaca das possibilidades de melhoria do processo produtivo" (2002, p.25). Tenório complementa sua argumentação afirmando que "apesar da identificação e caracterização dos grupos informais e outras relações interpessoais, esta abordagem não percebeu a origem da índole antiética das relações dentro do contexto mais amplo da sociedade" (2002, p.25).

Mesmo considerando as limitações e ambigüidades da noção de homo complexo, essa abordagem tem o mérito de ser a primeira tentativa concreta de se entender o papel do homem e dos grupos informais nas organizações dentro de um enfoque cognitivo.

A partir desse ponto, o conceito de homo complexo é aperfeiçoado nas décadas seguintes através de contribuições dos estudos sociotécnicos, da psicanálise e de pesquisas subseqüientes no campo da cognição. Seu conceito inicial é ampliado para um contexto mais rico, onde os indivíduos agem em sociedade a partir de suas escolhas e do sentido que atribuem à sua ação, formulando e institucionalizando as regras que constituem o sistema social onde vivem, regras essas que influenciarão, mais tarde, seus próprios mecanismos de decisão e padrões culturais.

Algumas correntes do pensamento organizacional caminham, então, na direção de atenuar a dicotomia entre a estrutura formal e a informal na organização, ainda muito evidente na noção inicial do homo complexo. Surgem abordagens orientadas por uma visão baseada no conceito de construção social da realidade. As organizações passam, também, a serem analisadas de uma perspectiva cultural, simbólica e política, numa combinação de aspectos formais e informais, considerados tanto os fatores estruturais quanto os relacionais.

Dessa perspectiva mais ampliada, este estudo buscará na teoria institucional os elementos teóricos necessários para iniciar a exploração do fenômeno das "confrarias".

\section{Entendendo o uso do termo "confrarias"}

Mas porque usar o termo "confraria"? Não seria este uma mera variação do conceito de grupos informais, tão freqüentemente explorado na teoria organizacional? A resposta é não. Longe de ser visto como um simples estereótipo ou expressão pejorativa, o termo "confraria" é tratado aqui como um construto teórico capaz de reunir e integrar - como veremos mais adiante - um conjunto rico de elementos com significativo poder de explicação das singularidades que distinguem as "confrarias" da noção mais convencional de grupos informais e, conseqüentemente, do seu papel e do seu poder de influência nas organizações.

A opção por uma estratégia interpretativa faz sentido em virtude das peculiaridades do objeto de estudo. Stablein (1999) afirma que, para alguns pesquisadores, o mundo organizacional é complexo e intrincado, e que a realidade organizacional, nesses casos, é "o mundo de construtos definidos pelo pesquisador" (1999, p.80), na sua busca pela explanação do fenômeno a partir das teorias existentes, mas que "os pontos de vista do pesquisador são o ponto de partida" (1999, p.80).

Segundo Houaiss e Villar (2001, p.798), o termo "confraria" tem suas raízes etimológicas no termo francês confrérie, surgido no século XIII, e reúne as seguintes definições possíveis: 
- associação laica que funciona sob princípios religiosos, fundada por pessoas piedosas que se comprometem a realizar, conjuntamente, práticas caritativas, assistenciais etc.; congregação, irmandade;

- associação ou conjunto de pessoas do mesmo ofício, da mesma categoria ou que levam um mesmo modo de vida ("confraria dos negociantes", "confraria dos boêmios");

- conjunto geralmente restrito de pessoas unidas por um liame comum, profissional, corporativo ou outro; sociedade, associação;

- sociedade teatral, que na França, na Idade Média, montava espetáculos religiosos, farsas e pantominas.

A análise dessas definições traz importantes revelações que possibilitam uma síntese preliminar dos componentes constitutivos do construto "confraria":

- afinidade - pertencer à "confraria" significa comungar das mesmas idéias, valores, sentimentos, comportamentos e modos de vida. É possível afirmar que os membros da "confraria" tendem a compartilhar uma mesma "visão do mundo";

- lealdade - os membros da "confraria" possuem sólidos laços de compromisso e solidariedade mútua; seguem seus próprios princípios e se organizam em torno de objetivos comuns;

- caráter excludente - as "confrarias" tendem a reunir grupos restritos de pessoas para garantir e fortalecer seus laços de coesão.

Os participantes desse mundo criam e reproduzem seus próprios sistemas de significados, e tecem, racional ou irracionalmente, seus próprios padrões e lógicas de ação, com influências importantes para o entendimento dos processos de gestão nas organizações. Aprofundar o conhecimento dessa realidade implica uma reflexão mais profunda sobre esses significados; objetivo deste estudo, conforme se verá mais adiante.

\section{As "confrarias" analisadas segunda a perspectiva institucional}

Nas últimas duas décadas, a abordagem institucional vem ganhando maior destaque no campo dos estudos sobre teoria organizacional. Nessa abordagem, a análise das organizações passa a dar uma maior ênfase nos aspectos relacionais e no exame dos sistemas sociais e culturais, como elementos que modelam e sustentam a estrutura e a ação nas organizações.

Vários autores têm tentando relacionar os principais fundamentos teóricos da abordagem institucional. Algumas propostas serão analisadas, aqui, como introdução a um debate mais denso que será realizado através de alguns dos textos clássicos mais representativos dessa abordagem, em particular aqueles que lançaram o conceito de campo organizacional como elemento central da teoria institucional.

No artigo em que analisam a obra de Selznick e suas contribuições à teoria organizacional, Fachin e Mendonça (2003) afirmam que essa perspectiva "pode ser tipificada como uma abordagem simbólico-interpretativa da realidade organizacional, apresentando uma posição epistemológica subjetivista em que é salientada a construção social da realidade organizacional" (2003, p.29). Os autores comentam que Selznick - considerado um dos precursores da teoria institucional - reconhecia que as organizações têm uma visão eminentemente racional, orientada para atingir objetivos, mas alertava para a incapacidade das estruturas formais de subjugar o lado irracional do comportamento organizacional: "indivíduos não agem puramente baseados em seus papéis formais, assim como as organizações não agem puramente baseadas em estruturas formais" (2003, p.30). De fato, o argumento racionalista pressupõe que o homem toma decisões racionais, voltadas para objetivos previamente definidos, a partir de um processo de deliberação consciente. Estudos produzidos na antropologia e na psicologia, principalmente, alegavam que, ao abordar a complexidade da tomada de uma decisão, o homem também faz uso de processos mentais não necessariamente conscientes, ou seja, existiriam outros elementos a se considerar no campo do inconsciente capazes de interferir no processo de decisão. Para Fonseca (2003), Selznick traz uma nova perspectiva à análise das organizações, desafiando a concepção racionalista ao "considerar as instituições uma variável independente", passando a "vislumbrar a organização como expressão de valores sociais" (2003, p.48). 
No clássico artigo de Meyer e Rowan (1977), que provocou uma mudança radical nas formas tradicionais de se pensar as relações entre a estrutura formal e a natureza do processo de decisão nas organizações, já se argumentava que as estruturas podem ser revestidas de significados socialmente compartilhados, isto é, tanto têm propriedades simbólicas como capacidade de gerar ação. A grande contribuição dos autores foi, exatamente, desafiar as teorias predominantes na época e tentar compreender as implicações do uso da estrutura formal para propósitos simbólicos:

As organizações são levadas a incorporar práticas e procedimentos definidos por conceitos racionalizados de trabalho organizacional predominantes e institucionalizados na sociedade. Organizações que procedem dessa forma, aumentam sua legitimidade e sua probabilidade de sobrevivência, independente da eficácia imediata das práticas e procedimentos adquiridos. (MEYER e ROWAN, 1977, p.340).

Meyer e Rowan (1977) alegavam que muitos dos estudos empíricos realizados até então apontavam um grande distanciamento entre a organização formal e a organização informal, e que o sucesso das organizações dependeria de fatores além da adoção de mecanismos eficientes de coordenação e controle. Os autores argumentavam que, em ambientes altamente institucionalizados, as organizações estariam sujeitas a pressões de natureza isomórfica, propensas a incorporar regras socialmente legitimadas em seu ambiente institucional, os chamados "mitos racionais". A conformidade com os "mitos racionais" nas organizações maximizaria sua legitimidade e sua capacidade de obter recursos, garantindo sua sobrevivência. Ao analisar os impactos do isomorfismo como mecanismo subjacente a processos de institucionalização, os autores comentavam que:

"Os efeitos do isomorfismo institucional nas organizações se verificam no desacoplamento entre estruturas formais e atividades, nos rituais de conformidade e boa-fé, e no esforço para evitar ou minimizar inspeções e avaliações, tanto por gerentes internos quanto por representantes externos." (MEYER e ROWAN, 1977, p.360).

Por outro lado, para Scott (2001), os processos de mudança trazem um problema para os teóricos de orientação institucionalista, muitos dos quais entendem as instituições como fonte de estabilidade e ordem. Se a natureza dos atores e de seus modos de ação são, ao mesmo tempo, constituídos e confinados pelas instituições, como esses atores são capazes de mudar essas mesmas instituições onde estão inseridos? Tal entendimento pressupõe que as instituições são criadas e, então, começam a exercer sua influência "legitimadora". Entretanto, não considera as próprias instituições como objeto de mudança futura.

Somente na última década, teóricos e pesquisadores começaram a examinar argumentos e situações envolvendo a mudança institucional que testemunhavam a "desinstitucionalização" de formas existentes e sua substituição por novos arranjos, os quais, com o tempo, também estariam sujeitos a processos de institucionalização.

Na tradição institucionalista vigente, existia um senso comum de que o foco principal dos estudos deveria residir nas forças legitimadoras, nos mecanismos isomórficos através dos quais os principais players nos campos organizacionais orientariam suas ações favoravelmente, uns aos outros, apoiados em instituições comuns - arquétipos de organização tomados por certos ("taken for granted") que davam forma, ao mesmo tempo em que constrangiam a ação coletiva (SCOTT, 2001; HENSMANS, 2003).

Como resultado desse debate, o foco da teoria está se deslocando do estudo dos campos como unidades de análise relativamente estáveis e previsíveis para uma perspectiva onde os campos passam a ser vistos como espaços de disputa, marcados por dependências de poder e interações estratégicas entre seus múltiplos constituintes, os quais passam a competir pela definição e resolução de questões e pela legitimação de diferentes arranjos organizacionais. Essa perspectiva não somente ilustra como a dinâmica do poder suporta o sistema de regras homogeneizadoras, mas também como essa mesma dinâmica impulsiona os atores institucionais a perseguir interesses heterogêneos (HENSMANS, 2003).

Dentro de um enfoque semelhante, Vieira e Carvalho (2003) afirmam que as instituições são produto da construção humana e, também, resultado de ações conduzidas por indivíduos orientados pelas próprias forças institucionais e por suas interpretações a respeito dessas forças. Portanto, o processo de institucionalização seria 
"estruturado e ao mesmo tempo estruturante, que não é necessariamente racional e objetivo, mas fruto de interpretações e subjetividades” (2003, p.13).

De uma maneira geral, a teoria institucional pode ser entendida como o resultado da convergência de influências de diversos corpos teóricos, trazidos principalmente da ciência política, da sociologia, da antropologia e da economia, os quais procuram incorporar em sua proposição básica a idéia de que instituições, padrões de comportamento, normas, valores, crenças e pressupostos moldam as preferências de indivíduos, grupos e organizações, determinando a assimilação de práticas e procedimentos, além de aumentar seu grau de legitimidade e sua chance de sobrevivência (MACHADO-DA-SILVA e GONÇALVES, 1999; VIEIRA e CARVALHO, 2003).

É preciso reconhecer que existem diversas abordagens para o conceito de "instituições", enraizadas em diversas disciplinas, e que é esperado que não exista consenso em torno de um conjunto específico de premissas e de objetivos. De fato, existem muitas vertentes do chamado neo-institucionalismo - na economia, na teoria das organizações, na ciência política, história e sociologia - unidos por não mais do que um ceticismo em relação a visões atomísticas do fenômeno social, e uma convicção comum de que os arranjos institucionais e os processos de socialização são o que realmente deve nortear os estudos nessa tradição (DiMAGGIO e POWELL, 1991).

Transpondo os fundamentos teóricos discutidos até aqui para a análise do construto "confrarias", consegue-se, assim, uma nova leitura de seus componentes constitutivos. Estes passam a ser vistos, agora, não como definições estáticas mas como dimensões valorativas, capazes de assumir gradações diferentes, na medida em que originam ou são oriundas de atos ou de efeitos de processos de valoração que emergem da sua interação com outros atores dentro do ambiente institucional. No quadro 1, procura-se explorar mais detalhadamente esse ponto de vista, propondo um modelo teórico simples para auxiliar o entendimento de algumas manifestações possíveis do fenômeno das "confrarias".

\section{Quadro 1}

Dimensões valorativas do construto "confrarias"

\begin{tabular}{|c|c|c|c|}
\hline $\begin{array}{l}\text { DIMEIISÄO } \\
\text { VALORATIVA }\end{array}$ & IDEIA CEIITRAL & \multicolumn{2}{|c|}{ MAIIIFESTAÇÖES POSSIVEIS } \\
\hline AFIIIIDADE & $\begin{array}{l}\text { Natureza dos laços } \\
\text { que atraem e } \\
\text { mantêm unidos os } \\
\text { membros da } \\
\text { "confraria". }\end{array}$ & $\begin{array}{l}\text { Os membros da } \\
\text { "confraria" são } \\
\text { movidos por } \\
\text { interesses bastante } \\
\text { objetivos e específicos, } \\
\text { eventuais ou transitórios. }\end{array}$ & $\begin{array}{l}\text { Existem, além de interesses } \\
\text { comuns, uma forte ênfase em } \\
\text { valores culturais ou } \\
\text { socialmente construídos, } \\
\text { compartilhados pelos } \\
\text { membros da "confraria". }\end{array}$ \\
\hline LEALDADE & $\begin{array}{l}\text { Grau de intensidade } \\
\text { e estabilidade das } \\
\text { inter-relações entre } \\
\text { os membros da } \\
\text { "confraria". }\end{array}$ & $\begin{array}{l}\text { Relações temporárias } \\
\text { ou oportunistas. }\end{array}$ & $\begin{array}{l}\text { Relações perenes, } \\
\text { duradouras, com } \\
\text { características de } \\
\text { fraternidade ou } \\
\text { irmandade. }\end{array}$ \\
\hline $\begin{array}{l}\text { CARATTER } \\
\text { EXCLUDEIITE }\end{array}$ & $\begin{array}{l}\text { Disposição da } \\
\text { "confraria" para } \\
\text { admitir novos } \\
\text { membros ao grupo. }\end{array}$ & $\begin{array}{l}\text { Comportamento mais } \\
\text { adaptativo e tolerante. }\end{array}$ & $\begin{array}{l}\text { Comportamento } \\
\text { extremamente } \\
\text { conservadore } \\
\text { elitista. }\end{array}$ \\
\hline
\end{tabular}

Fonte: elaboração do próprio autor.

Cabe esclarecer que esse modelo não entende as manifestações das dimensões valorativas como variáveis binárias. Não se trata, simplesmente, de "ter" ou "não ter" alguma característica ou comportamento; portanto, a proposta desse modelo é evitar dicotomias. Ao contrário, a opção por uma representação na forma de uma gradação foi intencionalmente feita para destacar o dinamismo pelo qual as dimensões valorativas do construto "confrarias" podem se manifestar num ato contínuo ao longo do tempo.

Essa proposta tem, assumidamente, um viés cognitivo - que enfatiza o aspecto simbólico das ações -, resultante das interpretações e representações que os indivíduos fazem da realidade, e a idéia de que as 
definições da realidade passam a ser compartilhadas por esses mesmos indivíduos. Nesse sentido, as "confrarias" podem ser consideradas um produto da construção desse universo simbólico-cultural, e, tal como as organizações, estão imersas num ambiente constituído por regras, crenças, valores e redes relacionais, consolidados por meio da interação social. A figura 1 mostra o modelo inicial visto no quadro 1 , numa perspectiva ampliada, representando o construto "confraria" e suas modalidades de interação com o ambiente institucional.

\section{Figura 1}

A “confraria” e suas modalidades de interação com o ambiente institucional

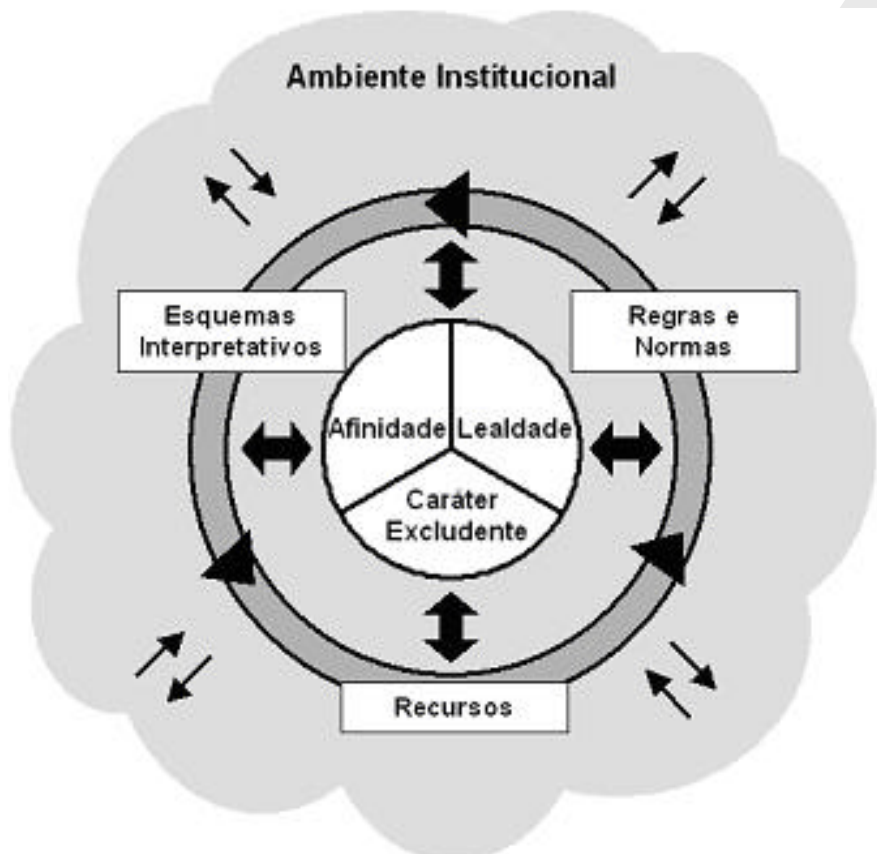

Fonte: elaboração do próprio autor.

No centro do modelo, estão as dimensões valorativas que concedem aos participantes da "confraria" o conhecimento-síntese: um conjunto compartilhado de significados por eles atribuídos à realidade social. Esse conhecimento-síntese é traduzido em modalidades de interação, codificadas na forma de esquemas interpretativos, regras e normas, e recursos. As modalidades de interação são explicadas mais detalhadamente a seguir:

\section{Esquemas interpretativos}

DiMaggio (1997) define "esquemas interpretativos" (ou schemata) como estruturas de conhecimento que representam objetos ou eventos e fornecem premissas básicas sobre suas características, relacionamentos e ordenações. Tais estruturas seriam acionadas em condições onde a informação sobre um determinado objeto ou evento é incompleta. Schemata são, simultaneamente, representações do conhecimento e mecanismos para processamento de informações. No primeiro caso, vincular a imagem de um determinado objeto às relações que se tem sobre ele faz com que algumas idéias ou conceitos se tornem mais acessíveis que outros. Como mecanismos, simplificam o processo de cognição, tornando-o implícito, rápido e automático. Machado-da-Silva et al. (1998) também abordam esse tema, dentro de um contexto de mudança estratégica, e definem esquemas interpretativos como um conjunto de idéias, crenças e valores capazes de fornecer uma "visão de mundo", impondo uma noção de ordem e coerência às estruturas e sistemas em uma organização.

\section{Regras e normas}

Podem ser entendidas como as práticas, procedimentos e padrões de conduta ou comportamento predominantes e socialmente legitimados no ambiente institucional (MEYER e ROWAN, 1977). 


\section{Recursos}

A despeito das críticas que se fazem à teoria institucional sobre sua capacidade de explicar processos de mudança em campos institucionalizados, acredita-se que essa teoria pode se tornar mais "estratégica" ao incorporar uma dimensão político-cultural à retórica da legitimação. Nesse contexto, o termo "recursos" pode ser ampliado a partir de alguns elementos da sociologia de Pierre Bourdieu, passando a ser visto, então, como formas de capital. Sobre esse tema, Bonnewitz afirma que "Bourdieu define o espaço social como um espaço multidimensional de posições, onde cada posição, em um dado momento, é ocupada por um agente ou grupo de agentes, conforme o volume e a estrutura de capital de que dispõem. $\mathrm{O}$ espaço social, portanto, é um espaço de disputa permanente por posições dominantes, hierarquizado em razão da desigual distribuição de capitais. Bourdieu distingue quatro tipos de capital: o capital econômico, constituído pelos diferentes fatores de produção e pelo conjunto dos bens econômicos; o capital cultural, que corresponde ao conjunto de qualificações intelectuais produzidas pelo sistema escolar ou transmitidas pela família; o capital social, que se define essencialmente como o conjunto de relações sociais de que dispõe um indivíduo ou grupo; e o capital simbólico, que corresponde ao conjunto de rituais ligados à honra e ao reconhecimento." (2003, p.52-55).

É por meio dessas três modalidades de interação que a "confraria" efetivamente se relaciona com seu ambiente institucional para buscar sua aceitação, ou seja, aumentar sua legitimidade e suas perspectivas de sobrevivência. As modalidades de interação influenciam diretamente o domínio de ação dos participantes da "confraria", definindo as estratégias que devem ser lançadas para a obtenção das formas de capital relevantes no momento os recursos de poder - capazes de lhes assegurarem uma posição dominante, instruindo-os como se comportarem, comunicarem e exercerem seu poder. Em um processo contínuo, todos os três componentes básicos do modelo (dimensões valorativas, modalidades de interação e o próprio ambiente institucional) atuam reciprocamente, um sobre o outro, levando a "confraria" a incorporar elementos já institucionalizados em seu ambiente ou a instituir novos padrões, buscando, assim, ampliar e preservar sua posição dominante (MEYER e ROWAN, 1977; MACHADO-DA-SILVA e GONÇALVES, 1999; FONSECA, 2003).

Argumenta-se, neste artigo, que o efeito combinado das manifestações possíveis de cada dimensão valorativa do construto "confraria" tem, portanto, um papel fundamental no seu processo de institucionalização. Contudo, esse processo estaria sujeito a pressões contínuas de outros atores relevantes dentro do seu ambiente institucional, atribuindo um caráter dinâmico à trajetória da "confraria" dentro da organização onde está inserida. Tais atores podem estar representados na figura de executivos de nível superior, conselhos de administração, acionistas, fornecedores, consumidores, concorrentes, governo e os diversos públicos que tenham algum interesse na organização. A formação, consolidação e perpetuação das "confrarias" estariam, assim, diretamente relacionadas com a obtenção dos recursos de poder necessários para reagir a essas pressões. Isso implica a constatação de que existiria um "ciclo de vida" associado às "confrarias", que passariam por diversos estágios de legitimação em seu ambiente institucional, à medida que suas estratégias para obtenção de recursos de poder sejam bem sucedidas. 


\section{Figura 2}

Dimensões valorativas combinadas versus legitimidade e sobrevivência

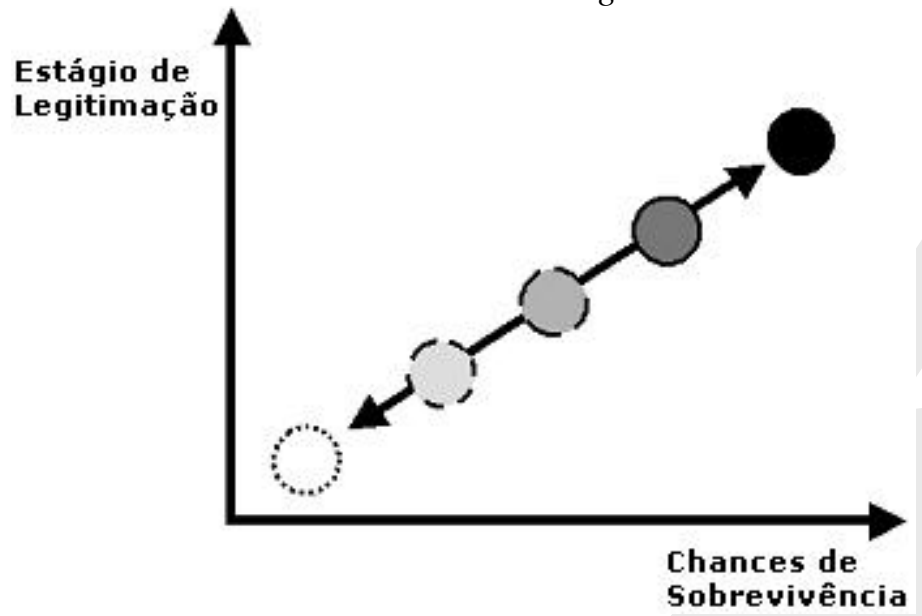

Fonte: elaboração do próprio autor.

De acordo com a figura 2, os círculos representam as dimensões valorativas combinadas, em seus vários estágios de legitimação. As diversas tonalidades observam o mesmo conceito de "gradação" adotado na definição dos elementos do construto teórico "confrarias" (vide quadro 1). Nas circunferências, que variam de um padrão pontilhado até um traço mais forte, busca-se sinalizar a acumulação crescente de recursos de poder pelos membros da "confraria". A seta dupla, que aparece no gráfico conectando os diversos estágios de legitimação, indica que a trajetória das "confrarias" admite dois sentidos - uma vez que o processo de institucionalização pode sofrer rupturas diante das pressões de outros atores relevantes - e chama a atenção para a permanente tensão existente entre os interesses das "confrarias" e os interesses das organizações onde estão inseridas. Na medida em que divergências de interesse começam a surgir, as "confrarias" precisam reagir e buscar novos recursos de poder para assegurar sua preservação. Caso contrário, perdem legitimidade em seu ambiente institucional e iniciam um processo de fragmentação que poderá culminar com seu desaparecimento.

Assim, com base nos elementos teóricos apresentados, derivam as duas primeiras proposições deste estudo:

\section{Proposição 1}

Quanto maior a ênfase em valores culturais ou socialmente construídos ("afinidade"), quanto mais intensas forem as inter-relações entre seus participantes e mais duradouros forem esses laços ("lealdade"), e quanto menor for a disposição para incorporar novos participantes e mais elitista for o grupo ("caráter excludente"), maior a probabilidade das "confrarias" ganharem legitimidade e garantirem sobrevivência em seu ambiente institucional.

É igualmente defendida a idéia de que as "confrarias" são fortemente influenciadas pelo contexto sociocultural onde estão imbricadas. Portanto, tendem a reproduzir traços característicos da sociedade brasileira (FREITAS, 1997):

- a tendência à centralização de poder e ao distanciamento nas relações entre diferentes grupos sociais, que se manifestam por um estilo "aristocrático" de gestão, ainda muito presente nas nossas organizações;

- a presença, ainda marcante, de um alto grau de personalismo e uma valorização exacerbada das relações pessoais nas organizações, que passam a ver o nepotismo como algo "normal" e tornam-se complacentes no controle e na cobrança de resultados, se comparados à lógica que normalmente orienta a atuação de grandes empresas, especialmente grupos multinacionais originários de países com raízes anglo-saxônicas e tradição religiosa moldada pela ética protestante.

Reafirmando o argumento da influência cultural, as decisões nas empresas brasileiras são marcadas por uma intensa interação social, pela existência de uma classe dominante com traços de burguesia e tecnocracia contemporânea, mas com valores e comportamentos ancorados num passado de aristocracia de senhores de 
engenho. Trata-se de algo intermediário e ambíguo, tal como muitos traços da cultura brasileira (MOTTA, 1997). Como consequiência da proposição 1, e considerando as características peculiares da sociedade brasileira, temos a segunda proposição:

\section{Proposição 2}

O processo de institucionalização das "confrarias" estará sujeito a pressões de natureza isomórfica que podem constituir um indicador da limitação dos seus participantes em realizar escolhas eficazes e produzir mudança e inovação nas organizações onde estão inseridos.

Entender o processo de formação e configuração do fenômeno "confraria" exige um olhar interdisciplinar, conforme já visto. Utilizar a noção de campo organizacional como unidade de análise pode ajudar a compreender melhor esse processo, principalmente, como elementos históricos e sociológicos exercem influência na estruturação da "confraria" como um fenômeno organizacional.

\section{A teoria institucional e o conceito de "campos organizacionais": explorando a possibilidade de diálogo com o fenômeno das "confrarias"}

O processo de estruturação dos campos organizacionais representa uma etapa importante da análise institucional e antecede os processos de isomorfismo institucional, histórica e logicamente (VIEIRA e CARVALHO, 2003, p.16).

Desde a década de 1970, o conceito de campo tem sido explorado sob variados enfoques. DiMaggio e Powell (1983) relacionam diferentes perspectivas de análise que alguns autores buscaram para explicar o conceito de campo organizacional:

Quadro 2

Perspectivas de análise do conceito de campo organizacional

\begin{tabular}{lll}
\hline Autores & Unidade de análise & Abordagem \\
\hline Hannan e Freeman & Firmas competidoras & Ecologia populacional \\
Laumann at al. & Rede de organizações que efetivamente interagem & Organizações em rede \\
DiMaggio e Powell & Totalidade dos atores relevantes & Neo-institucionalismo \\
\hline
\end{tabular}

Fonte: DiMaggio e Powell (1983, p.148)

Para DiMaggio e Powell (1983), os campos não existem a priori, e somente podem ser verificados através de investigação empírica, quando já estão institucionalmente definidos. À medida que os campos organizacionais tornam-se mais fortemente estruturados, geram o contexto no qual esforços individuais para lidar racionalmente com a incerteza e com as restrições do ambiente levam as organizações a adotarem estruturas, processos e culturas homogêneas: "Uma vez que um conjunto de organizações emerge na forma de um campo organizacional, surge um paradoxo: atores racionais tornam suas organizações cada vez mais semelhantes ao tentarem promover mudanças." (DiMAGGIO e POWELL, 1983, p.147).

Portanto, a competição entre as organizações não pode ser vista somente como uma disputa por recursos ou clientes, mas como um processo mais complexo que envolve, também, disputas por poder e por legitimidade em seu ambiente institucional. Os campos organizacionais surgem e estruturam-se como resultado de processos isomórficos que tornam as organizações cada vez mais semelhantes entre si, sem, necessariamente, aumentar sua eficiência. O isomorfismo é descrito por DiMaggio e Powell como um "processo restritivo que força uma unidade numa população a assemelhar-se a outras unidades que enfrentam o mesmo conjunto de condições ambientais" (1983, p.149).

Assim, é fundamental compreender como os campos organizacionais surgem e são estruturados ao longo do tempo, processo que pode ser visto em quatro etapas (DiMAGGIO e POWELL, 1983, p.148; VIEIRA e CARVALHO, 2003, p.17): 
- aumento na interação entre as organizações dentro do campo;

- surgimento de estruturas interorganizacionais de dominação e de padrões de coalizão claramente definidos;

- aumento do fluxo de informação com o qual as organizações no campo devem lidar;

- desenvolvimento de uma consciência mútua entre os participantes de um grupo de organizações de que todos estão envolvidos em uma iniciativa comum.

DiMaggio e Powell (1983, p.150-153) identificam três mecanismos por meio dos quais ocorrem as mudanças isomórficas nos campos organizacionais, à medida que aumenta seu grau de estruturação:

\section{Isomorfismo coercitivo}

Resultante de pressões tanto formais quanto informais exercidas nas organizações por outras organizações com as quais possuem algum tipo de dependência, e por expectativas culturais na sociedade na qual cada organização atua. Essas pressões estariam relacionadas com influências políticas e com a necessidade de legitimação. A existência de ambientes extremamente regulados afeta, em muitos aspectos, a estrutura e o comportamento das organizações dentro do campo. Em sociedades com passado colonial, forte tradição patriarcal e valores democráticos ainda em formação (o Brasil, por exemplo), é esperado que os campos organizacionais sejam estruturados em torno de mecanismos coercitivos. $\mathrm{Na}$ maior parte dos casos, em economias onde o Estado ainda exerce um papel intervencionista muito forte.

\section{Isomorfismo mimético}

Resultante de pressões geradas pelas incertezas e restrições impostas pelo ambiente, onde as organizações tendem a imitar processos e práticas que "deram certo" em organizações similares e que, ao longo do tempo, tornaram-se "legítimas" dentro do campo. Portanto, é uma "rota de menor custo", ou seja, as organizações podem espelhar-se em outras organizações em situação na qual a tecnologia existente ainda não está completamente absorvida, cujos objetivos são ambíguos e pouco claros, ou ainda quando o ambiente gera incertezas, mesmo que simbólicas. Nesse caso, a imitação de modelos institucionalmente aceitos dentro do campo minimiza o risco e o custo da mudança. Comportamentos miméticos foram e ainda são freqüientemente observados nas organizações. Exemplos podem ser facilmente identificados na proliferação dos modelos prescritivos de análise estratégica desenvolvidos por empresas de consultoria especializada, nos modismos tecnológicos e no sucesso mais recente das ferramentas para gestão de performance, tais como o EVA (economic value added ou valor econômico agregado) e o balanced scorecard.

\section{Isomorfismo normativo}

Resultante de pressões geradas pela profissionalização, que podem ser interpretadas como um movimento coletivo de membros de uma determinada ocupação profissional, no sentido de definir as condições e os métodos de trabalho e estabelecer bases cognitivas e legitimadas que assegurem sua autonomia. Três aspectos desse processo de profissionalização são particularmente importantes. Primeiro, a influência das instituições de ensino na construção dos padrões e normas que orientam a ação dos gestores nas organizações. Segundo, o crescimento das associações profissionais que se estendem pelas organizações, por onde novos modelos são rapidamente difundidos e institucionalizados. Por último, o incentivo a práticas discriminatórias, observadas, principalmente, nos processos de seleção e recrutamento e nos critérios de planejamento de carreira adotados nas empresas. Nas organizações, há uma preferência explícita por profissionais formados em instituições de ensino reconhecidas e legitimadas ou que sejam originários da mesma indústria ou setor. Tal comportamento tem desdobramentos futuros dentro da organização, uma vez que essa casta de profissionais é, freqüentemente, beneficiada nos processos de promoção e tem acesso às melhores oportunidades de carreira.

Essa tipologia tem um caráter essencialmente analítico, empregada mais como um instrumento de apoio para interpretar a realidade. Na prática, os processos de isomorfismo nos campos organizacionais acontecem de 
forma dinâmica, onde esses mecanismos não se manifestam de forma distinta ou exclusiva, mas, ao contrário, surgem combinados conforme as condições impostas pelo ambiente.

Parece evidente que, à medida que aumenta o grau de estruturação de um campo, as organizações conseguem maior legitimidade e alcançam maior estabilidade dentro do seu ambiente institucional. Por outro lado, as pressões isomórficas subjacentes ao processo de estruturação do campo reduzem a diversidade e limitam a habilidade de mudança e inovação nas organizações (DiMAGGIO e POWELL, 1983; VIEIRA e CARVALHO, 2003).

Retornando ao objeto de estudo deste artigo, as "confrarias", o confronto com o conceito de campo organizacional aqui discutido abre possibilidades de diálogo bastante interessantes com o conceito de "confrarias". Mesmo reconhecendo as dificuldades e riscos na conciliação de abordagens, ainda que construídas a partir dos mesmos paradigmas, entende-se que a análise realizada sobre a evolução das dimensões valorativas combinadas no construto "confrarias", sua relação com o processo de legitimação e sua capacidade de sobrevivência dentro das organizações (vide figura 2) podem ser confrontadas com o processo de estruturação dos campos organizacionais, sem prejudicar a teoria. Esse diálogo, além de ampliar a perspectiva de análise do fenômeno das "confrarias", abre a possibilidade de validar as teses apresentadas neste artigo à luz de teorias reconhecidas e legitimadas no campo do estudo das organizações. Dessa forma, chega-se ao restante das proposições que se pretende aqui explorar:

\section{Proposição 3}

O processo de formação e estruturação das "confrarias" sugere uma lógica semelhante ao processo de institucionalização dos campos organizacionais.

Esta proposição pode ser entendida mais detalhadamente no quadro 3:

Quadro 3

Etapas de formação das "confrarias"

\begin{tabular}{|c|c|c|c|}
\hline $\begin{array}{l}\text { Confraria em } \\
\text { pré-formação }\end{array}$ & $\begin{array}{c}\text { Confraria } \\
\text { emergente }\end{array}$ & $\begin{array}{c}\text { Confraria } \\
\text { em expansão }\end{array}$ & $\begin{array}{c}\text { Confraria } \\
\text { institucionalizada }\end{array}$ \\
\hline $\begin{array}{l}\text { Os membros da } \\
\text { confraria estão iso- } \\
\text { lados e indepen- } \\
\text { dentes. }\end{array}$ & $\begin{array}{l}\text { São criados enlaces entre } \\
\text { os membros, surgem es- } \\
\text { truturas de dominação e } \\
\text { padrões de coalizão e de } \\
\text { comportamento claramen- } \\
\text { te definidos. }\end{array}$ & $\begin{array}{l}\text { Os enlaces se fortale- } \\
\text { cem, aumentando a } \\
\text { convergência de valo- } \\
\text { res entre os membros. }\end{array}$ & $\begin{array}{l}\text { Os enlaces são consolidados } \\
\text { e o grupo compartilha os va- } \\
\text { lores. Surge uma consciência } \\
\text { mútua entre os membros de } \\
\text { que todos estão envolvidos } \\
\text { numa iniciativa comum. }\end{array}$ \\
\hline
\end{tabular}

Fonte: adaptado de Vieira e Carvalho (2003)

A mesma linha de pensamento leva à:

\section{Proposição 4}

Similarmente, as "confrarias" também estão sujeitas a pressões isomórficas de seu ambiente institucional para buscar legitimidade e obter os recursos de poder necessários para perpetuar sua existência e manter sua posição dominante.

Os mecanismos isomórficos descritos por DiMaggio e Powell (1983) também se manifestam no processo de formação das “confrarias". Dessa forma, é possível desdobrar a proposição 4 em três proposições correlatas, de acordo com a tipologia proposta por esses autores:

\section{Proposição 4-A}

As "confrarias" estariam sujeitas a mecanismos isomórficos de caráter coercitivo, na medida em que reproduzem os padrões sociais e culturais de seus participantes e precisam adequar-se a pressões internas $e$ externas à organização, visando buscar o apoio político necessário à sua legitimação. 


\section{Proposição 4-B}

As "confrarias" estariam sujeitas a mecanismos isomórficos de caráter mimético quando buscam incorporar à sua forma de atuação, práticas e padrões de comportamento reconhecidos e legitimados dentro ou fora da organização onde estão inseridas: símbolos que lhes atribuem "status social" e asseguram os recursos de poder necessários para sua aceitação.

\section{Proposição 4-C}

As "confrarias" estariam sujeitas a mecanismos isomórficos de caráter normativo, claramente identificados quando analisadas pela dimensão "caráter excludente". De modo semelhante à dinâmica analisada no processo de estruturação dos campos organizacionais, os participantes da confraria também estabelecem práticas discriminatórias, estruturam sua base cognitiva e definem seus próprios padrões, regras e métodos de trabalho.

Tal como foi visto no processo de estruturação dos campos organizacionais, é evidente que, à medida que aumenta o seu grau de estruturação, as "confrarias" conseguem maior legitimidade em seu ambiente institucional. Essa condição tem, seguramente, influência na performance competitiva das organizações e na sua capacidade de gerenciar processos de mudança e inovação. Nesse sentido, argumenta-se que:

\section{Proposição 5}

O processo de institucionalização das "confrarias" confere aos seus membros um nível confortável de estabilidade. Mas ao rejeitarem a possibilidade da diversidade, as "confrarias" também limitam sua ação e sua habilidade como agentes de mudança e inovação, assumem um papel conservador e paternalista - por vezes, complacente diante de comportamentos inadequados de seus participantes -, abrindo espaço para tensões éticas inevitáveis que podem comprometer o funcionamento eficiente das organizações.

\section{Considerações finais}

A proposta deste artigo é realizar uma investigação preliminar do fenômeno das "confrarias", partindo, primeiramente, da sua delimitação e contextualização como objeto de estudo, para, então, iniciar um diálogo com alguns dos elementos mais representativos da teoria institucional. Algumas teses foram levantadas ao longo do estudo e representadas na forma de modelos teóricos, cujo principal objetivo foi traduzir, num formato simples e didático, os resultados produzidos a partir do diálogo com as teorias. De uma maneira geral, as "confrarias" podem ser interpretadas simultaneamente como:

- fenômeno organizacional - expresso na forma de grupos informais que emergem nas organizações a partir de valores socialmente construídos e compartilhados, categorizados, neste artigo, nas dimensões "afinidade", "lealdade" e "caráter excludente". Nessa perspectiva, as "confrarias" evoluem dentro das organizações, aumentando seu grau de estruturação interna, buscando garantir legitimidade em seu ambiente institucional, assegurar a estabilidade de seus participantes e sua própria sobrevivência, bem como obter os recursos de poder necessários à manutenção da sua posição dominante.

- fenômeno cultural - na medida em que as "confrarias" têm uma gênese social e reproduzem traços característicos da sociedade brasileira.

Portanto, não há como estudar qualquer fenômeno organizacional em uma empresa sem estudar a complexidade dos sistemas sociais com os quais interage, sem recorrer a elementos históricos, antropológicos e culturais que construíram a sociedade onde a organização está inserida.

As contribuições deste estudo para a academia se verificam na medida em que trazem novos elementos para o debate sobre a capacidade da teoria institucional explicar processos de mudança em campos já institucionalizados. Muitos críticos afirmam que essa teoria ainda estaria mal equipada para elucidar estratégias e mecanismos relacionados a processos de mudança (HENSMANS, 2003). É defendido aqui que essa teoria pode se tornar mais "estratégica", integrando conceitos de poder e cultura para construir uma nova retórica de legitimação. 
A expectativa é de que este estudo tenha indicado caminhos possíveis para investigações empíricas que comprovem as teses aqui levantadas, contribuindo para desenvolvimentos teóricos futuros. 


\section{Referências bibliográficas}

BONNEWITZ, P. Primeiras lições sobre a sociologia de P. Bourdieu. Tradução de Lucy Magalhães. Petrópolis: Vozes, 2003.

DaMATTA, R. 0 que faz o Brasil, Brasil. Rio de Janeiro: Rocco, 2001.

DIM AGGIO, P. J \& \& POWELL, W. The iron cage revisited: institutional isomorphism and collective rationality in organizational fields. American Sociological Review, v.48, n.2, p.147-160, Apr. 1983.

\& _ _._. Introduction. In: DIMAGGIO, P. J \& POWELL, W. (Org.). The new institucionalism in organizational analysis. Chicago: The University of Chicago Press, 1991. p.1-38.

Culture and cognition. Annual Review of Sociology, v.23, p.263-349, 1997.

FACHIN, R. C. \& MENDONÇA, J. R. Selznick: uma visão da vida e da obra do precursor da perspectiva institucional na teoria organizacional. In: VIEIRA, M. M. \& CARVALHO, C. A. (Org.). Organizações, instituições e poder no Brasil. Rio de Janeiro: FGV, 2003. p.29-45.

FONSECA, V. S. A abordagem institucional nos estudos organizacionais: bases conceituais e desenvolvimentos contemporâneos. In: VIEIRA, M. M. \& CARVALHO, C. A. (Org.). Organizações, instituições e poder no Brasil. Rio de Janeiro: FGV, 2003. p.47-66.

FREITAS, A. B. Traços brasileiros para uma análise organizacional. In: MOTTA, F. C. \&

CALDAS, M. P. (Org.). Cultura organizacional e cultura brasileira. São Paulo: Atlas, 1997. p.38-54.

HENSM ANS, M. Social movements: a metaphor for strategic actors in institutional fields. Organization Studies, v.24, n.3, 2003.

HOUAISS, A. \& VILLAR, M. S. Dicionário Houaiss da Língua Portuguesa. Rio de Janeiro: Objetiva, 2001.

MACHADO-DA-SILVA, C. L.; FONSECA, V. S. \& FERNANDES, B. H. Mudança e estratégia nas organizações: perspectivas cognitiva e institucional. In: ENCONTRO DA ASSOCIAÇÃO NACIONAL DE PROGRAMAS DE PÓS GRADUAÇÃO EM ADM INISTRAÇÃO, 22., Foz do Iguaçu, 1998. Anais... Foz do Iguaçu: Anpad, 1998. 1 CD-ROM.

\& GONÇALVES, S. A. Nota técnica: a teoria institucional. In: CLEGG, S.; HARDY, C. \& NORD, W. (Org.). Handbook de estudos organizacionais. São Paulo: Atlas, 1999. v.1, p.220-226.

MASLOW, A. H. Motivation and personality. Nova York: Harper, 1954.

MAYO, E. The human side of enterprise. Nova York: McMillan, 1933.

MEYER, J. W. \& ROWAN, B. Institutionalized organizations: formal structure as myth and ceremony. American Journal of Sociology, v.83, n.2, p.340-363, Sept. 1977.

MOHRMAN, S.; TENKASI, R. \& MOHRMAN JR., A. The role of networks in fundamental organizational change. A grounded analysis. The Journal of Applied Behavioral Science, v. 39, n.3, p.301-323, Sept. 2003.

M OTTA, F. C. Cultura e organizações no Brasil. In: MOTTA, F. C. \& CALDAS, M. P. (Org.). Cultura organizacional e cultura brasileira. São Paulo: Atlas, 1997. p.25-37.

\& VASCONCELOS, I. F. Teoria geral da administração. São Paulo: Pioneira Thomson Learning, 2002.

OLIVER, A. \& EBERS, M. Networking network studies: An analysis of conceptual configurations in the study of inter-organizational relationships. Organization Studies, v.19, n.4, p.549-583, 1998.

POOLE, M.; HOLLINGSHEAD, A.; MCGRATH, J.; MORELAND, R. \& ROHRBAUGH, J. Interdisciplinary perspectives on small groups. Small Group Research, v.35, n.1, p.3-16, 2004.

PRATES, M. A. \& BARROS, T. O estilo brasileiro de administrar: sumário de um modelo de ação cultural brasileiro com base na gestão empresarial. In: M OTTA, F. C. \& CALDAS, M. P. (Org.). Cultura organizacional e cultura brasileira. São Paulo: Atlas, 1997. p.55-69.

SCOTT, R. W. Institutions and organizations. 2. ed. California: Sage Publications, 2001.

STABLEIN, R. Dados em estudos organizacionais. In: CLEGG, S.; HARDY, C. \& NORD, W. (Org.). Handbook de estudos organizacionais. São Paulo: Atlas, 1999. v.2, p.63-88.

TENÓRIO, F. G. Tem razão a administração? Ensaios de teoria organizacional e gestão social. ljuí: Ed. ljuí, 2002.

VIEIRA, M. M. \& CARVALHO, C. A. Introdução: sobre organizações, instituições e poder. In: VIEIRA, M. M. \& CARVALHO, C. A (Org.). Organizações, instituições e poder no Brasil. Rio de Janeiro: FGV, 2003. p.11-26. 